\title{
INDEX TO VOLUME LVIII.
}

\section{A}

Abscess, Retroperitoneal, 704; Subdiaphragmatic, 334, 423.

Allexander, EMory G.: Report of 105 Cases of Strangulated Hernia, 639; Tuberculin Treatment for Cervical Lymphadenitis, 55 .

Allen, Carroll W.: Reducing the Calibre of the Thoracic Aorta by Plication, 304.

American Surgical Association, Its Influence on the Growth and Development of American Surgery, I; Transactions of the, 271.

Amputations, an Aralysis and Study of 724 Major, 39, 276.

Anxemia, Splenic, 6or.

Anesthesia, Accuracy in, 877; Deaths from, 934; General, Finger Elevation of the Hyoid Bone in, 660; in Goitre Operations, 939; Intratracheal, 927; Intravenous, 900; Medicolegal Aspects of, 956; Reflex Action During General Surgical, 8g1; Supplement, 865.

Anxsthetists, American Association of, 865 .

Aneurism, Aortic, Wiring of, 698 ; of the Internal Iliac, 269.

Aneurismorrhaphy, 86.

Aorta, Partial Occlusion of Thoracic and Abdominal, by Bands of Fresh Aorta and of Fascia Lata, 183; Thoracic, Plication of, 304.

Appendicitis, Acute, Followed by Intestinal Obstruction, 404; Gangrenous, Followed by Ileus, 413; Simulated by Contracture of Psoas Muscle, 483, 864; Simu- lated by Foreign Body Perforating Ileum, 706; with Pyloric Adhesions, 695.

Armstrong, Grorge E.: Treatment of Fractures, 274

Arteriovenous Femoral Anastomosis for Gangrene, 93, 4II.

Ashrurst, Astzey P. C.: Biliary Peritonitis without Perforation of the Bile Ducts, 43I ; Fractures through the Trochanters of the Femur, 494; Meckel's Diverticulum, 7II; Splenic Anxemia, 713; Subphrenic Abscess, 424; Treatment of Tuberculous Cervical Lymphadenitis, 550; Two Sacs in Inguinal Hernia, 7Ir.

Aspiration in Abdominal Operations by Suction Tip, 537.

\section{B}

Baingridge, William Seahlan: Anresthesia in Goitre Operations, 939.

BALDWIN, J. F.: Sarcoma of the Chest Wall, 853.

Banti's Diseasc, Splenectomy for, 420, 54I.

BartzetT, Willard: Development of the Author's Gastro-enterostomy Clamp, 659.

BEER, Edwin: Transperitoneal Resection of Diverticulum of the Bladder, 634.

Brlings, Arthur E.: Suture of the Heart, $7 \mathrm{r} 2$.

BinnIE, John Fatrbatrn: Snapping Hip, 59.

Bladder Diverticulum, Transperitoneal Resection of, 634; Exclusion of the, 133, 286; Purpura of the, 388; Rupture of the, 244 . 
Blake, Jorn Bapst: Diagnosis and Treatment of Fractures Involving the Knee-joint, 27.

Blake, Joseph A.: Fibromatosis of the Stomach, 27r ; Splenectomy for Banti's Disease, 420.

Bland-Sutton: Fibroids of the Uterus, Review of, 858 .

BLoodcood, Josern C.: Development of Malignancy in Hygromata, 28I; Diagnosis and Treatment of Border-Line Pathological Lesions, 282; Fibromatosis of the Stomach, 271; Sarcoma of Femur, 280; Studies in Bloodpressure with Reference to Shock, 721.

Blood Injections for Cure of Ununited Fracture, 564.

Blood-pressure with Reference to Shock, 721 .

Bones, Fracture of the Long, Reduction of the Fragments Preliminary to Internal Splintage, 490: Fractures of the Long, Reduction of Fragments at Open Operation, 656.

Bone Transplantation for Pott's Disease, 570.

Border-Line Pathological Lesions, Diagnosis and Treatment of, 282.

Brachial Artery, Direct Suture of the, 534 .

Breast, Lacteal Cyst of, 428 ; Tuberculosis of the, 396 .

Breasts, Bilateral Cystic Degeneration of the, 397; Diffuse Adenofibroma of Both, 398.

Buchanan, John J.: Infection after Implantation of Ureter into Intestine, 287 .

\section{C}

Cacosigmoid Anastomosis, 69r.

Calculus, Renal, Exactness in Diagnosis and Conservatism in Treatment of, 616 .
Callison, Jaises G.: Tumots of the Carotid Body, 740 .

Cardiolysis, 662.

Cardioplasty, Intrathoracic, for Cardiospasm, 699.

Cardiospasm, Esophagogastrostomy for, 415 .

Cardiovascular System, The Surgery of the, 278.

Carotid Body, Tumors of the, 426 , 740.

CARY, F. S.: Value and Limitation of Diastase, Urea and Phthalein in Estimating Renal Function, 800.

Casamajor, Lours: Traumatic Erb's Paralysis, 577.

Cervical Lymphadenitis, Tuberculous, Treatment of, 433, 550; Rib, 555.

Chest Wall, Sarcoma of the, 853; Surgery of the, 206.

Cheyne and Burghard: Manual of Surgical Treatment, Review of, 856.

Cholecystotomy, Ideal, 694.

Choyce and BeatTy: System of Surgery, Review of, 857 .

Chylo-Ascites of Traumatic Origin, 553.

Clavicle, Open Operation for Fracture of, 669; Sarcoma of, 556.

Clendening, Logan: Myoma of the Stomach, 812.

Coley, Williax B.: Adenocarcinoma Rendered Operable by the use of the Mixed Toxins, 559; Contribution to the Study of Sarcoma of the Femur, 97 ; Diagnosis of Tumors of the Pylorus, 273; Lymphocele Simulating Femoral Hernia, 682; Rectus Transplantation in Certain Cases of Hernia, 677; Sarcoma of Clavicle, 556; Use of Absorbable Sutures in Hernia Operations, 679. 
Coluns, Howard D.: Acute Phlegmon of the Ascending Colon, 554; Chylo-Ascites of Traumatic Origin, 553.

Colon, Ascending, Acute Phlegmon of the, 554; Total Extirpation of the, Experimental Observations Bearing upon, 346.

CoLT, G. H.: Reduction of Fragments Preliminary to Internal Splintage in Fractures of the Long Bones, 490.

CONNEIL, KARL: Accuracy in Anxesthesia, 877 .

Corron, F. J.: Deaths from Anresthesia, 934 .

CriLe, Grorge W.: Laryngectomy for Cancer, I64; Observations upon Surgery of the Stomach, 272.

Cunningham, Orval J.: Nitrous Oxide and Oxygen Narcosis, 917.

\section{D}

Da Costa, John Chalmers: Dentigerous Cyst, 54I ; Lacteal Cyst of Breast, 428; Splenectomy for Banti's Disease, 541; Subfascial Tubercle, 54I; Tumors of the Carotid Body, 426.

Darrach, William : Fracture Dislocation of the Shoulder, 666; Lane Plate for Fracture of the Radius, 668; Open Operation for Fracture of Clavicle, 669 .

Davis, Johi Staige: Excessive Thickening of Thiersch Grafts Caused by Use of Scarlet Red, 451.

DAwbare, Robert H. M.: Recurrences after Operation for Hernia, 678.

Deaths from Anasthesia, 934.

Deaver, John B.: Pancreatic and Peripancreatic Lymphangitis, 15I.

Dezatour, Henky B.: Results of Treatment of Fractures of the Patelia, 274.
Dentigerous Cyst, 541.

Despard, Duncan L.: Subdiaphragmatic Abscess, 334.

Diastase, Urea and Phthalein, Value and Limitation of in Estimating Renal Function, 800.

Dilatation of Stomach, Acute, After Operation for Hernia, 702.

Dislocation of the Shoulder, Operative Reduction of Old, $\mathbf{5 4 2}$.

Diverticulitis of the Sigmoid, 356.

Diverticulum of the Bladder, Transperitoneal Resection of, 634 .

Douglas, JoHN: Diverticulitis of the Sigmoid, 356 .

Dowd, Charles N.: Cardiolysis, 662; Hygroma Cysticum Colli, II2; Observations upon Surgery of the Stomach, 272; Results of Bone Injuries in Children, 275.

Downes, Whliram A.: Rectus Transplantation in Certain Cases of Inguinal Hernia, 677 .

Dunhay, Theodore: Rib-Finder, 685.

Duodenal Kink, 572.

Duodenal Ulcer, Cases of, 664; Perforating, Pyloroplasty for, 4I4; Pyloric Exclusion for, 697.

Duodenum, Double Perforation of the, 555 .

E

Echinococcus of the Liver, 697.

Elbow, Movable After Suppuration, 571.

Electric Bath, Relief of Endarteritis obliterans by, 670 .

Elsberg, Charles A.: Some Surgical Features of Injuries of the Spine, 296.

Embolism and Thrombosis of the Superior Mesenteric Artery, 459.

Endarteritis Obliterans relieved by Electric Bath, 670.

Enterostomy for Intestinal Obstruction Following Acute Appendicitis, 405 . 
Erb's Paralysis in the Adult, Traumatic, 577.683.

Erdmann, Jogn F.: Carcinoma of Papilla of Vater, 686; Excision of Remains of Wolfian Duct, 689; Partial Gastrectomy, 687; Rupture of Intestine in a Child, 686; Rupture of the Liver in a Child, 686.

Estes, William Lawrence: Analysis and Study of 724 Major Amputations, 39 .

\section{F}

Farr, Charles E.: Strangulation of the Undescended Testis, 838 .

FARR, R. E.: Primary Sarcoma of the Large Intestine, 818.

Femur, Fractures Through the Trochanters of the, 494; Periosteal, Round-celled Sarcoma of, 280; Sarcoma of the, Contribution to the Study of, 97.

Fibromatosis of the Stomach, 10, 271.

Finger, Use of in Rhinoplasty, 408.

FinNey, J. M. T.: Fibromatosis of the Stomach, 272.

Fixation of Transverse Fractures, A Method for the Mechanical, 653.

Foot, Osteoplastic Operation on the, 690 .

Foreign Body Perforating the Ileum, 706.

Fracture Dislocation of the Shoulder, 574, 666.

Fracture of Both Patella, Simultaneous, 510; of Carpal Seaphoid with Luxation of Semilunar, 716; of Clavicle, Open Operation for, 669; of the Radius, Lane Plate, 668; of the Spine, 296.

Fractures Involving the Knee-joint, Diagnosis and Treatment of, 27, 273 ; of the Long Bones, Reduction of Fragments at Open Operation, 656; of the Long Bones, Reduction of Fragments Prelim- inary to Internal Splintage, 490; of the Tarsal Scaphoid, 526; through the Trochanters of the Femur, 494; Transverse, Mechanical Fixation of, 653; Ununited, Cured by Blood Injections, 564.

Frazier, Charles H.: Treatment of Tuberculous Cervical Lymphadenitis, $55 \mathrm{r}$.

Freeman, Leonard: Arteriovenous Anastomosis for Threatened Gangrene of the Foot, 92.

\section{G}

Gall-bladder, Acute Spontaneous Perforation of, Into Free Peritoneal Cavity, 428.

Gangrene of the Foot, Arteriovenous Anastomosis for Threatened, 92; Threatening, Arteriovenous Femoral Anastomosis for, 4 II.

Gastrectomy, Partial, 687.

Gastric and Pancreatic Carcinoma, The Relationship between, 324 .

Gastro-enterostomy, Cause and Treatment of Certain Unfavorable After-effects of, 466; Clamp, 659; for Benign Stenosis of Pylorus, 664; Persistent Vicious Circle after, 663; with Occlusion of Pylorus, 664 .

Gernghty, J. T.: Value and Limitation of Diastase, Urea and Phthalein in Estimating Renal Function, 8oo.

Gerstrk, Arpad G.: Blood Injections for Cure of Ununited Fracture, 564; Border-Line Pathological Lesions, 285; Fibromatosis of the Stomach, 273; Patent Urachus and Epigastric Hernia, 566; Pulmonary Abscess, 567; Sutures in Hernia Operations, 680; Treatment of the Pylorus after Gastro-enterostomy, 665 ; Urinary Infiltration After Retroperitoneal Ureterotomy, 566. 
Gerster, John C. A.: Reduction of Fragments in Fractures of Long Bones at Open Operation, 656 .

GrbBon, JoH N H.: Causes of Rupture of the Gall-bladder, 430; Technic of Nephro-, Pyelo-, and Ureterolithotomy, 232.

Ginson, Charles L.: Cervical Rib. 555; Double Perforation of the Duodenum, 555; Epithelial Changes in Chronic Mastitis, 400 .

GrLL, A. BRUCE: Perforated Meckel's Diverticulum, 708; Removal of Paraffine from Inguinal Canal, 7I0; Two Independent Sacs in an Inguinal Hernia, 709. Goitre Operations, The Question of Anxsthesia in, 939.

Graft, Tibial, Use of, for Skull Defect, 690 .

Grahay, James M.: Fibromatosis of the Stomach, Io.

Graves's Disease, Excision of Both Lobes of Thyroid Gland for Cure of, 178; The Preliminary Ligation of the Thyroid Arteries in Cases of, 180.

GWathamey, James T.: The American Association of Anæsthetists, 865.

\section{H}

Hremophilia, Preventive Injection of Human Blood Serum Before Operation in a Case of, 695 .

Halsten, Willias S.: Case of Congenital Dislocation of the Hip Cured by Operation, 276; Excision of Both Lobes of Thyroid Gland for Cure of Graves's Disease, 178; Observations upon Amputations, 276; Preliminary Ligation of Thyroid Arteries in Cases of Graves's Disease, 180.

Hartwell, John A.: Epithelial Changes in Chronic Mastitis, 399: Pyopneumothorax, 402; Tuberculosis of the Breast, 396 .
HASSLER, J. WyLLIS: Intravenous Anesthesia, 900.

Heart and Blood-vessels, Surgery of the, 278 .

Heart, Suture of the, 67,712 .

Hematogenous Infections of the Kidney, Excision of the Infarct in Acute, 226.

Hemorrhoids, Whitehead Operation for, Immediate and Late Results of the, 647 .

Hermaphrodite, Undescended Testis in 2,400 .

Hernia, Epigastric, 566; Femoral, Simulated by Lymphocele, 682; Inguinal, Attempted Cure by Injections of Parafine, 710; Inguinal, Rectus Transplantation in Certain Cases of, 473, 677; Inguinal, Recurrence of, 479; Inguinal, with Two Independent Sacs, 709; Operations, Use of Absorbable Sutures in, 679; Strangulated, Report of 105 Cases of, 639 .

Hernial Sac in its Relation to Concealed Intestinal Injuries, 365.

Hertz, Arteurr F.: Cause and Treatment of Certain Unfavorable After-effects of Gastroenterostomy, 466.

HEWSON, ADDINELL: Obstruction by Meckel's Diverticulum, 7Ir.

Hip, Congenital Dislocation of the, Rational Method of Treatment, 277; Snapping, 59.

Hodge, Edward B.: Perforation of Ileum with Escape of Foreign Body Simulating Appendicitis, 707.

Honan, Wrutasr Francis: Intravenous Anzesthesia, 900.

HoRnsBy and Scrumt: The Modern Hospital, Review of, 858 .

Horwitz, Alex. E. Uncomplicated Fractures of the Tarsal Scaphoid, 526 . 
Hospital, Modern, Review of Hornsby and Schmidt's Treatise on, 858 .

Hotch xiss, Lucius W.: Excision of the Infarct in Acute Infections of the Kidney, 226.

HuLL, A. J.: Recurrence of Inguinal Hernia, 475.

Hydatid Cysts of the Liver, Suppurating, 574.

Hydrocele of the Tunica Vaginalis, Recurrences after Operation, 56r. Hydronephrosis, Early Diagnosis of, 766 .

Hygroma Cysticum Colli, I12, 288. Hyoid Bone, Finger Elevation of, in General Anæsthesia, 660.

Hypernephroma, Nephrectomy for, 692.

Hysterectomy, Supravaginal Development of Malignant Diseases of the Cervical Stump after, 373.

\section{I}

Ileum, Perforation of, by Foreign Body Simulating Appendicitis, 706.

Ileus Following Gangrenous Appendicitis, $4 \mathrm{I} 3$.

Iliac, Internal, Aneurism of the, 269.

Inguinal Hernia with Two Independent Sacs, 709.

Intestinal Obstruction Following Acute Appendicitis, 405.

Intestine, Extensivé Removal of, Later History of Case of, 717; Large, Sarcoma of the, 818 ; Nonrotation of the, 822; Removal of Large Portion of, Later History of, 7rg; Rupture of, in a Child, 686.

Intratracheal Anæsthesia, 927.

Intravenous Anzesthesia, 900.

\section{$\mathrm{J}$}

Jaconson, Nathan: Observations upon Amputations, 276.
JANEWAy, HENRY H.: Intratracheal Anresthesia, 927.

Jaw, Lower, Bilateral Ankylosis of the, Operation for, 698 .

Jopson, Jonn H.: Operative Reduction of Old Dislocation of the Shoulder, 542; Perforation of Gall-bladder into General Peritoneal Cavity, 432; Subphrenic Infection, 423 .

\section{$\mathbf{K}$}

KAYMSERER, FrEDERICK : Erb's Paralysis, 684 ; Removal of Cervical Rib, 556.

KIDD, Frank: Purpura of the Bladder, 388.

Kidney, Acute Hematogenous Infections of the, Excision of the Infarct in, 226; and Ureter, Removal of Stones from the, 286; Pelvic, Report of Case of, 809; Tuberculosis of the, 404 .

Knee-joint, Fractures Involving the, Diagnosis and Treatment of, $27,273$.

\section{L}

Lacteal Cyst of Breast, 428.

LAMBERT, A. V. S.: Esophagogastrostomy for Cardiospasm, 415.

LANDON, L. H.: Sarcoma of the Lower Lip, 545.

Laparotomy Incision and Closure, Retrorectus, 828.

IAROQUE, PaUl: Anatemic and Physiologic Principles Concerning Pyloric Ulcer, 320.

Laryngectomy for Cancer, I64, 279. LE Conte, Robert G.: Infection after Implantation of Ureter into Intestine, 287.

LeoNard, Veader Newron: Development of Malignant Disease of the Cervical Stump after Supravaginal Hysterectomy, 373 . 
INDEX.

Lilienthal, Howard: Experiences with the Mixed Toxins, 560; Observations upon Amputations, 276; Pylorectomy Following Pyloroplasty,' 571; Technic of Arteriovenous Anastomosis, 279; Two Stage Pylorectomy, 272.

Liver, Echinococcus of the, 697 ; Rupture of, in a Child, 686.

LUND, FRED B.: Intratracheal Insufflation Apparatus in Operations upon the Chest, 279; Sarcoma of the Chest Wail, 206.

Lung, Gangrene of, Pneumotomy, 700.

Lusx, WrLlan C: Endarteritis Obliterans relieved by Electric Bath, 670; Technic of Rectus Transplantation, 675 .

LyLE, HenRy H. M.: Blood Injections for Cure of Ununited Fracture, 565; Inguinal Lymphocele, 683.

Lymphadenitis, 550; Tuberculous, Cervical, Treatment of, 433 .

Lymphangitis, Pancreatic and Peripancreatic, $15 \mathbf{r}$.

Lymphocele Simulating Femoral Hernia, 682.

\section{M}

MaeKenty, John Eduund: Tumors of the Carotid Body, 740.

MacLaren, Archibald: Aneurism of the Internal Iliac, 260.

Mastitis, Chronic Epithelial Changes in, and their Relation to the Development of Mammary Carcinoma, 399; Chronic, with Carcinoma, 395.

Matas, Rudolph: Fibromatosis of the Stomach, 272; Reducing the Calibre of the Thoracic Aorta by P.ication, 304.

Mayo, Charles H.: Carcinoma of the Thyroid, 28r ; Exclusion of the Biadder, I33.
Mayo, Wizlaye J.: The Surgery of the Pancreas, 145.

McDill, JoHN R. Cyst of the Fifth Metacarpal Bone, 533.

McGRAw, T. A. Carcinoma of Colon, 272.

McMechan, F. Hozrfzr: Medicolegal Aspects of Anasthesia, 956.

McWillinss, Clarence A.: Arteriovenous Femoral Anastomosis for Threatening Gangrene, 411 ; Ileus Following Gangrenous Appendicitis, 413; Rhinoplasty by Finger, 408 .

Meckel's Diverticulum, Perforated, 708.

Medicolegal Aspects of Anzesthesia, 956.

Mereness, Harry E., Jr: Stovaine Spinal Analgesia in Prison Surgery, 947.

Mesenteric Artery, Superior Embolism and Thrombosis of the, 459.

Metacarpal Bone, Cyst of the Fifth, 533.

MeYER, Winly: Echinococcus of the Liver, 697; Ideal Cholecystotomy, 694; Intrathoracic Cardioplasty for Cardiospasm, 699; Jianu's Gastrostomy and Esophagoplasty for Cancer of the CEsophagus, 700; Nephrectomy for Hydronephroma, 692; Esophagoplasty, 289; Operation for Total Ankylosis of the Lower Jaw, 698; Pneumotomy for Gangrene of the Lung, 700; Preven-

- tive Injection of Human Blood In Operation in a Hemophiliac, 695: Pyloric Adhesions and Appendicitis, 695 ; Pyloric Exclusion of Duodenal Ulcer, 697 ; The Surgery of the Pulmonary Artery, I88; Thoracoplasty, 701 ; Treatment of Cardiospasm, 4I7 ; Treatment of Fractures of the Elbowjoint, 274; Wiring of Aortic Aneurism, 698 . 
Miller, Morris Booth: Perforation of Intestine by Foreign Bodies, 707; Sporotrichosis, 540.

Mutchelt, Jaxes F.: The Surgical Aspects of Purpura, 258.

Moore, Jayes E.: Treatment of Joint Fractures, 275.

MoORHEAd, JoHN J.: Retrorectus Laparotomy Incision and Closure, 828.

Morris, Robert T.: Crecosigmoid Anastomosis, 691; Elbow, Movable after Suppuration, 57I; Osteoplastic Operation on the Foot, 690; Use of Tibial Graft for Skull Defect, 690 .

Moschcowitz, Alexis V.: Hydrocele of the Tunica Vaginalis Recurring after Operation, 56r ; Omental Grafting, 562; Rectus Transplantation in Certain Cases of Hernia, 678 .

Müller, George P.: Splenic Anæmia, 714; Treatment of Tuberculous Cervical Lymphadenitis, 433.

MuRphy, JoHn B.: Border-Line Pathological Lesions, 285 ; Fractures of the Elbow-joint, 275; Hygroma Cysticum Colli, 281 .

Myoma of the Stomach, 812.

Myxochondro-Endothelioma of Occipital Bone, 427.

\section{$\mathbf{N}$}

Narcosis by Nitrous Oxide and Oxygen, 917.

Neck, Cystic Tumors of the, 112.

Nephrectomy for Hypernephroma, 692.

Nephro-, Pyelo-, and Ureterolithotomy, The Technic of, 232.

New York Surgical Socrety, Transactions of the, $395-402,553$, 662, 686.

Nitrous Oxide and Oxygen Narcosis, 917.
Noland, Lloyd: Embolism and Thrombosis of the Superior Mesenteric Artery, 459.

Non-rotation of the Intestine, 822. Nose, Review of Skillern on the Catarrhal and Suppurative Diseases of the Accessory Sinuses of the, 86 .

OchsNer, Alnert J.: Sarcoma of the Ilium, 280 .

๔sophagogastrostomy for Cardiospasm, 415.

Esophagoplasty, 289, 700 .

Esophagus, Cancer of the, Esophagoplasty for, 700 .

Ollerenshaw, Robert : Sacrococcygeal Tumors, 384 .

Omental Grafting, 562.

Osteoplastic Operation on the Foot, 690.

Outrand, John H.: Myoma of the Stomach, 812.

Oxygen, Nitrous Oxide and, Narcosis, 917.

\section{$\mathbf{P}$}

Pancreas, Cyst of the, 563; The Surgery of the, 145 .

Pancreatic and Gastric Carcincma, The Relationship between, 36 .

Pancreatic and Peripancreatic Lymphangitis, 15 I.

Pancreatitis, Acute, 688.

Paraffine, Removal of, from Inguinal Canal in Case of Inguinal Hernia, 710.

Paralysis, Erb's, Traumatic, 577, 683.

Parsons, Carl G.: Reflex Action During General Surgical Anaesthesia, 89r.

Partial Occlusion of Aorta by Bands of Fresh Aorta and of Fascia Lata, 183.

Patellæ, Simultaneous Fracture of Both, 5 Io. 
Patterson, Ellen J.: Finger Elevation of the Hyoid Bone in Gencral Anxsthesia, 660 .

Peck, Charles H.: Erb's Paralysis, 684 .

Pelvic Kidney, Report of Case of, 809.

Pfeiffer, David B.: Pancreatic and Peripancreatic Lymphangitis, 151 .

Philladelphia Acadeary of SURGERY: Transactions of the, 423 , 540, 702 .

Pilcher, Paul Monroe: Exactness in Diagnosis and Conservatism in Treatment of Renal Calculus, $6 \mathrm{I} 6$.

Pneumotomy for Gangrene of Lung, 700.

PoOL, Eugene H.: Gastro-enterostomy, Benign Stenosis of Pylorus, 664; Gastro-enterostomy, Persistent Vicious Circle, 663; Gastroenterostomy with Occlusion of Pylorus, 664; Pyloroplasty with Excision of Duodenal Ulcer, 665; Suction Tip for Aspiration in Abdominal Operations, 537.

Pott's Disease, Bone Transplantation for, $\mathbf{5 7 0 .}$

Powers, Charles A.: Influence of the American Surgical Association on the Growth and Development of American Surgery, 1 .

Prisrose, Alexander: Removal of Stone from Ureter, 286.

Prison Surgery, Spinal Analgesia in, 947.

Psoas Parvus Muscle, Contracture of, Simulating Appendicitis, 483, 864.

Pulmonary Abscess, 567; Artery, The Surgery of the, 188 .

Purpura, of the Bladder, 388; The Surgical Aspects of, 258.

Pyelography in the Diagnosis of Hydronephrosis, 766 .
Pylorectomy Following Pyloroplasty, 571 .

Pyloric Ulcer, The Anatomic and Physiologic Principles Concerning, 320.

Pyloroplasty for Perforating Duodenal Ulcer, 414; with Excision of Duodenal Ulcer, 665.

Pylorus, Treatment of, after Gastro-enterostomy, 663.

Pyonephrosis, Calculous Bilateral, 419.

Pyopneumothorax, 402.

\section{$\mathbf{R}$}

Radius, Lane Plate for Fracture of, 668 .

Ransohoff, Joseph: Acute Perforating Sigmoiditis in Children, 218.

Rectum, Anatomy of a Case of Carcinoma of the, 831 .

Rectus Transplantation, by Special Technic, 675; in Certain Cases of Inguinal Hernia, 473, 677.

Refiex Action During General Surgical Anxesthesia, 801.

Remsen, Chardes M.: The Hernial Sac in its Relation to Concealed Intestinal Injuries, 365.

Renal Calculus, Exactness in Diagnosis and Conservatism in Treatment of, 616; Function, Value and Limitation of Diastase, Urea and Phthalein, in Estimating, 800.

Retroperitoneal Abscess, 704 .

Retrorectus Laparotomy Incision and Closure, 828.

Rhinoplasty by Finger, 408.

Rib-Finder, 685.

Rodman, J. Stewart: Retroperitoneal Abscess, 706; Splenic Anzmia, 6or.

Ross, Grorge G.: Acute Spontaneous Perforation of Gallbladder into Free Peritoneal Cavity, 428; Subdiaphragmatic Abscess, 424; Tooth Pick Perforating Cxcum, 707. 
Rowntree, L. G.: Value and Limitation of Diastase, Urea and Phthalein in Estimating Renal Function, 800.

\section{$\mathbf{s}$}

Sacrococcygeal Cyst, 418; Tumors, 384; of Clavicle, 556; of the Chest Wall, 206, 853; of the Femur, 280; of the Femur, Contribution to the Study of, 97 ; of the Large Intestine, 818; of the Lower Lip, 545 ; of the Stomach, 252.

Scaphoid, Carpal, Fracture of, with Luxation of Semilunar, 716; Tarsal, Fractures of the, 526.

Scarlet Red the Cause of Extensive Thickening of Thiersch Grafts, $45 \mathrm{I}$.

Schachner, August: Experimental Anatomic and Physiologic Observations Bearing upon Total Extirpation of the Colon, 346 .

Schley, W. S.: Bilateral Cystic Degeneration of the Breasts, 397 ; Diffuse Adenofibroma of Both Breasts, 398; Rectus Transplantation in Certain Cases of Inguinal Hernia, 473; Tuberculosis of the Breast, 400 .

Schumany, Edward A.: The Relationship Between Gastric and Pancreatic Carcinoma, 326.

Scudder, Cearles L.: Immobilization after Joint Fractures, 273; Sarcoma of the Stomach, 252.

Semilunar, Luxation of, Fracture of Scarpal Scaphoid with, 716.

Sheprerd, Francis J.: Note on Cancer of the Thyroid, 109 .

Sherman, Harry M.: Immobilization after Joint Fractures, 273; Treatment of Exstrophy of the Bladder, 287.

Sherrml, J. Garland: Direct Suture of the Brachial Artery Following Rupture, Result of Traumatism, 534
Shock and its Relations to Bloodpressure, 72t.

Shoulder, Fracture Dislocation of the, 574, 666; Operative Reduction of Old Dislocation of the, 542.

Sigmoid, Diverticulitis of the, 356 . Sigmoiditis in Children, Acute Perforating, 218.

SkILLERN on The Catarrhal and Suppurative Diseases of the Accessory Sinuses of the Nose, Review of, 86r.

Skmlers, P. G., JR. Fracture of Carpal Scaphoid and Cuneiform with Luxation of Semilunar, 716.

Skull Defect Supplied by Tibial Graft, 439 .

Snapping Hip, 59.

Soutrar, H. S.: A Method for the Mechanical Fixation of Transverse Fractures, 653 .

Spezse, Jorn: Acute Gastric Dilatation Following Operation for Hernia, 702; Perforation of Ileum by Foreign Body Simulating Appendicitis, 706; Retroperitoneal Abscess, 704.

Spinal Analgesia in Prison Surgery, 947.

Spine, Injuries of the, Surgical Features of, 296.

Splenectomy for Banti's Disease, 420,54 I.

Splenic Anxemia, 601, 713.

Sporotrichosis, 540.

Steinke, Cari Rossow: Simultaneous Fracture of Both $\mathrm{Pa}$ telle, 510.

Stewart, James L.: Contracture of Psoas Muscle Simulating Appendicitis, 864 .

Stewart, Francis T.: Five Cases of Suture of the Heart, 67 .

Stewart's Manual of Surgery, Review of, 862 . 
Stomach, Acute Dilatation of, After Operation for Hernia, 702 ; and Pancreas, the Relationship Between Carcinoma of, 326; Fibromatosis of the, 10, 271; Myoma of the, 812; Sarcoma of the, 252.

Stone, H. B.: Immediate and Late Results of the Whitehead Operation for Hemorrhoids, 647.

Stovaine Spinal Analgesia in Prison Surgery, 947.

Strangulated Hernia, Report of 105 Cases of, 639.

Subdiaphragmatic Abscess, 334, 423.

Suction Tip for Aspiration in Abdominal Operations, 537.

Surgery, Review of Choyce and Beatty's System of, 857; Review of Stewart's Manual of, 862.

Surgical Treatment, Review of Cheyne and Burghard's Manual of, 856 .

Syms, Parker: Chronic Mastitis with Carcinoma, 395; Duodenal Kink, 572; Fracture-Dislocation of the Shoulder-joint, 574; Suppurating Hydatids of the Liver, 574.

$\mathbf{T}$

TAYLOR, Alfred S.: Traumatic Erb's Paralysis in the Adult, 577.

Testis, Undescended, in a Hermaphrodite, 400; Undescended, Strangulation of the, 838 .

Thiersch Grafts, Excessive Thickening of, from use of Scarlet Red, 541.

Thomas, G. J.: Report of Case of Pelvic Kidney, 809.

Thomas, T. Turner: Pathology of Old Dislocations of the Shoulder, 44.

Thompson, JAMEs E: Suture of the Heart, 279. .

Thomson, Alexis: Amputations in Two Stages, 276; Arteriovenous
Anastomosis, 279; Fibromatosis of the Stomach, 10.

Thoracoplasty, 701.

Thyroid Arteries, Preliminary Ligation of, in Cases of Graves's Disease, 180; Body, Note on Cancer of the, I09; Carcinoma of the, 281; Gland, Excision of Both Lobes of, for Cure of Graves's Disease, 178.

Tibial Graft, Use of, for Skull Defect, 690 .

Tod, T. Wrigate: Anatomy of a Case of Carcinoma of the Rectum, 83r.

Toxins, Mixed, Use of, in Adenocarcinoma of the Soft Palate, 559; Use of, in Sarcoma of Clavicle, 556.

Tubercle, Subfascial, 54I.

Tuberculosis of the Breast, 396; of the Cervical Lymph Nodes, Treatment of, 433,550 ; of the Kidney, 402, 404.

\section{U}

Ununited Fracture Cured by Blood Injections, 564

Urachus, Patent, 566.

Ureteral Calculus and Pyelitis Simulating Appendicitis, 569.

Ureterolithotomy, The Technic of, 232.

Ureterotomy, Retroperitoneal, Followed by Urinary Infiltration, 566 .

Uterus, Development of Malignant Disease of the Cervical Stump of, After Supravaginal Hysterectomy, 373; Review of Bland-Sutton's Treatise on Fibroids of the, 858.

\section{$\mathbf{V}$}

Vater, Carcinoma of the Papilla of, 687.

Vaughas, George Tully: Aneurismorrhaphy, 86.

Vosburgh, Arthur Seymour: Nonrotation of the Intestine, 822 . 
W

WALKER, J. W. Thomson: Eatly Diagnosis of Hydronephrosis by Pyelography and Other Means, 766.

Watson, Francts S.: Nephrostomy, 286; Occurrence of Bilateral Kidney Calculus, 286.

WAtSon, Fred C.: Embolism and Thrombosis of the Mesenteric Artery, 459.

Welch, William: Coexistence of Different Pathological Conditions in One Tumor, 280.

Whitali, J. Dawson: Later History of Case of Extensive Removal of Intestine, 719.
WhitE, GeorGe R.: Contracture of the Psoas Parvus Muscle Simulating Appendicitis, 483 .

Whitehead Operation for Hemorrhoids, Immediate and Late Results of the, 647 .

WILlard, De Forest P.: Splenic Anæmia, 6or.

Wolffian Duct, Excision of Remains of, 689.

Woolsey, George: Bilateral Calculous Pyonephrosis, 419; Rupture of the Bladder, 244; Sacrococcygeal Cyst, 418; Undescended Testis in a Hermaphrodite, 400. 